\title{
Retraction Note to: Synthesis and characterization of a novel locally high dense sulfonated poly (aryl ether ketone sulfone) for DMFCs applications
}

\author{
Chengyun Yuan ${ }^{1} \cdot$ Yinghan Wang ${ }^{1}$
}

Published online: 29 January 2021

(c) The Polymer Society, Taipei 2021

Retraction Note to: Journal of Polymer Research (2020) 27:318 https://doi.org/10.1007/s10965-020-02282-3

The authors have retracted this article [1] because Scheme 1, Scheme 2, Figs. 2, 3, 4, and 8, as well as significant parts of the text were duplicated from a previously published article by Yuan and Wang [2]. Both authors agree with this retraction.

\section{References}

1. Yuan C, Wang Y (2020) Synthesis and characterization of a novel locally high dense sulfonated poly (aryl ether ketone sulfone) for DMFCs applications. J Polym Res 27:318. https://doi.org/10. 1007/s10965-020-02282-3

2. Yuan C, Wang Y (2020) The preparation of novel sulfonated poly(aryl ether ketone sulfone)/TiO2 composite membranes with low methanol permeability for direct methanol fuel cells. High Performance Polymers. https://doi.org/10.1177/0954008320958044

Publisher's Note Springer Nature remains neutral with regard to jurisdictional claims in published maps and institutional affiliations.

The original article can be found online at https://doi.org/10.1007/ s10965-020-02282-3

Yinghan Wang

wang_yh@scu.edu.cn

1 State Key Laboratory of Polymer Materials Engineering,

College of Polymer Science and Engineering, Sichuan,

University, Chengdu 610065, China 